\title{
A AFIRMAÇÃO DE ESTEREÓTIPOS ATRAVÉS DOS DISCURSOS MIDIÁTICOS: ANÁLISE DO CASO NICOLE BAHLS E GERALD THOMAS
}

\author{
Keren Franciane Moura ${ }^{1}$ \\ Giselle Marquette Nicaretta ${ }^{2}$ \\ Ana Paula da $\operatorname{Rosa}^{3}$
}

\begin{abstract}
Resumo
A imagem de determinadas mulheres dentro dos meios de comunicação é constantemente utilizada para difundir ideais de beleza e comportamento, afirmando e estabelecendo discursos sexistas que estereotipam a mulher como objeto de dominação masculina. Esse artigo propõe-se a examinar essa questão partindo do caso específico ocorrido entre a modelo Nicole Bahls e o diretor Gerald Thomas, através da análise do conteúdo noticiado por diferentes sites, visando identificar os estereótipos apresentados sobre uma mesma figura feminina nos diferentes discursos construídos pela mídia.
\end{abstract}

Palavras-chave: Mídia, discurso, mulher, estereótipo.

\begin{abstract}
The image of some women on the media is constantly used to disseminate reality and beauty standards, reinforcing and establishing sexist discourses that stereotype women as an object of men's domination. The purpose of this paper is to study this mater from the specific case involving Nicole Bahls and Gerald Thomas, analyzing what was published about it on different websites, aiming to identify the stereotypes built by the media about this subject.
\end{abstract}

Keywords: Media, discourse, woman, stereotype.

\section{Introdução}

A comunicação já não é mais a mesma, tampouco o jornalismo. Cada vez mais a comunicação assume a centralidade dos processos sociais, que são interseccionados por dispositivos midiáticos seja de instituições jornalísticas ou de atores individuais. Contudo, o que tem chamado a atenção, em especial, é a protagonização que a própria mídia tem conquistado na mídia, ou seja, o seu espaço autorreferencial ou ventríloco.

O caso analisado traz à tona a necessidade de discutir a enunciação jornalística como protagonista. O fato ocorreu no dia 10 de abril de 2013, durante o evento de lançamento do livro Arranhando a superfície, de Gerald Thomas, diretor de teatro de carreira internacional. Este lançamento contou com a presença de várias celebridades brasileiras, atraindo os olhares da mídia. Entre os enviados para cobrir o evento estava Nicole Bahls, que estreava "seu retorno"

\footnotetext{
${ }^{1}$ Aluna de Tecnologia do $3^{\circ}$. período do Curso de Tecnologia em Comunicação Institucional da Universidade Tecnológica Federal do Paraná (UTFPR)

${ }^{2}$ Aluna de Tecnologia do $3^{\circ}$. período do Curso de Tecnologia em Comunicação Institucional da Universidade Tecnológica Federal do Paraná (UTFPR)

${ }^{3}$ Professora Orientadora. Jornalista, Doutora em Ciências da Comunicação pela Universidade do Vale do Rio dos Sinos(UNISINOS).

Professora e pesquisadora na Universidade Tecnológica Federal do Paraná (UTFPR).
} 
ao programa Pânico na TV, da emissora de televisão aberta Rede Bandeirantes, e entrevistou o diretor juntamente com outros dois colegas de trabalho. Conhecido como um provocador nato e polêmico em suas produções, Gerald Thomas fez, durante a entrevista, um trocadilho com o sobrenome de Nicole Bahls e colocou a mão dentro de seu vestido para verificar se ela teria "balls".

A cena ocorrida recebeu mais destaque do que o evento que estava sendo coberto pela imprensa, e as fotos foram amplamente divulgadas por sites especializados em celebridades. Essas fotos circularam pela internet gerando diversos tipos de manifestações através das mídias e redes sociais, bem como pelos portais de notícias.

O objetivo desse artigo é o de analisar a forma como esse episódio foi noticiado pela mídia e publicado nos principais portais eletrônicos de notícia do país e como esse acontecimento midiático se constituiu. Para esta análise, foram selecionados os portais Globo.com, Folha Online e o site da revista Carta Capital. Por meio destas três fontes de publicação é possível mostrar diferenças entre as coberturas que qualificam ou desqualificam a personagem Nicole Bahls, exatamente por sua imagem já ter sido anteriormente explorada na e pela mídia e por ela própria, como se criador e criatura se fundissem, reforçando estereótipos.

\section{Entre enunciação e protagonismo na esfera da midiatização}

Tomando como base que "o conceito de enunciação é definido não pela complexidade intrínseca ao funcionamento da matéria significante, mas pela noção de intencionalidade, aspecto sobre o qual repousaria a completude" (FAUSTO NETO, 2007, p.79), observa-se que ao discurso é imputada a imagem de quem ou com quem se fala. Por estar mergulhada no contexto social e histórico onde é desenvolvida, a enunciação jornalística atua nos papéis de emissor e receptor simultaneamente, reproduzindo no discurso suas ideologias e leituras sobre determinado fato.

Em seu artigo "Enunciação, auto-referencialidade e incompletude", Antônio Fausto Neto destaca as diferenças da enunciação jornalística na passagem da "sociedade dos meios" para a "sociedade da midiatização". Na "sociedade dos meios", a enunciação jornalística tem como papel principal a mediação, deixando o discurso com o papel de protagonista dentro do processo representacional. Já no segundo momento, na "sociedade da midiatização", acontece a reformulação dos vínculos sociais, onde as tecnologias são os meios de interação e os mídias transformam-se em complexos sistemas, onde "A realidade externa se faz presente, mas a partir de operações de acoplamentos feitas pela enunciação, que tratam de instituí-la em conformidade com as suas próprias regras e com suas gramáticas" (FAUSTO NETO, 2007, p.80), ou seja, 
com maior autonomia para realizar sua leitura da realidade. Dito de outro modo, na esfera da midiatização a sociedade é atravessada pelas lógicas dos meios que passam a ser os protagonistas dos discursos, colocando-se não só como mediadores, mas como aqueles que reformulam, chancelam e orquestram os próprios vínculos sociais através dos dispositivos, aqui, no caso, os portais. Contudo, na ambiência da midiatização os atores sociais (público em geral) também produzem materiais significantes e, portanto, estão envolvidos na enunciação e na produção de sentido.

Orlandi (2010, p.21) define o discurso como sendo o "efeito de sentidos entre locutores", mostrando que para a Análise do Discurso o molde de receptor passivo, que capta a mensagem transmitida pelo emissor, não se aplica, uma vez que esta visa não somente a transmissão da informação, mas sim "o processo de constituição entre os sujeitos e produção de sentidos". Com base nisso, pode-se afirmar que um discurso será influenciado por outros durante esse processo, não se manterá indiferente a eles, seja por relações de exclusão/inclusão, de repetição, de sustentação mútua, de oposição, ou por migração de elementos de um discurso para outro. Orlandi afirma que "todo texto é uma unidade complexa: não há texto, não há discurso, que não esteja em relação com outro, que não forme um intricado nó de discursividade" (ORLANDI, 2010, p.88), ou seja, os discursos são formados por outros discursos, por outras vozes, que são elementos importantes para que o analista possa identificar como esses se organizam para formar sentidos.

Tais afirmações foram observadas e confirmadas com a análise das matérias veiculadas sobre o caso Nicole Bahls e Gerald Thomas, onde os traços da "sociedade da midiatização" tornaram-se nítidos e delimitados em face das diferentes enunciações jornalísticas construídas sobre o caso. Mesmo nas matérias publicadas com caráter aparentemente noticioso, isto é, com fins específicos de relatar o fato na concepção de Charaudeau (2012), percebe-se a influência dessas outras vozes defendendo ou atacando determinadas ideologias de discursos sexistas sobre a imagem da mulher e seu posicionamento na sociedade.

\section{Análises empíricas do caso}

\section{Portal Globo.com}

\section{Site EGO}

O site EGO noticia o ocorrido como uma "saia justa", utilizando-se de expressões coloquiais no decorrer do texto, tais como "por essa ela não esperava" ou "a morena", concedendo ao discurso um tom de fofoca, de falatório, característico do site. A enunciação é feita através de um texto curto, acompanhado por várias fotos, entre elas, uma de Nicole Bahls 
sentada com sua lingerie aparecendo. A associação do texto com as imagens passa a mensagem de que dado o tipo de mulher que ela é, a atitude de Gerald Thomas foi um acontecimento normal.

\section{Quanto ao modo discursivo}

$\mathrm{Na}$ reportagem do site EGO, o acontecimento foi relatado de forma curta e superficial, não revelando opinião definida ou intenção de promover um debate. A notícia foi simplesmente divulgada assim que aconteceu, dentro dos padrões textuais já seguidos pelo site.

\section{Quanto ao conteúdo do texto}

O primeiro parágrafo já se inicia com a notícia de que algo inesperado aconteceu com a apresentadora. Logo depois, explica-se o contexto da entrevista e só então faz-se menção ao ataque sofrido por Nicole Bahls:

\footnotetext{
Por essa Nicole Bahls não esperava. De volta ao programa "Pânico", a morena foi ao lançamento do livro "Arranhando a Superfície", de Gerald Thomas, em uma livraria no Leblon, Zona Sul do Rio. Ao tentar entrevistar o diretor teatral, Nicole foi atacada por ele. Gerald Thomas enfiou a mão dentro do vestido de Nicole, que ficou visivelmente constrangida com a atitude do entrevistado.
}

No segundo e último parágrafo, utiliza-se um período composto, iniciado com a frase "Usando um vestido curtinho, Nicole Bahls ainda deixou sua calcinha à mostra", para relacionar o fato ocorrido ao seu comportamento de apresentar-se com um vestido curto. Com a intenção de afirmar a normalidade da situação, o texto termina com um comentário da própria apresentadora feito através do Twitter, mostrando-se otimista sobre sua volta ao programa, agradecendo a todos pelo apoio. Nesse comentário da apresentadora fica clara a confusão de sua imagem como mulher e sua imagem de mulher objeto vendida pela mídia, tratando do assunto de forma estritamente profissional, camuflando o lado real e emocional do fato:

\footnotetext{
Usando um vestido curtinho, Nicole Bahls ainda deixou sua calcinha à mostra ao entrevistar, ao lado do humorista Ceará, o ator Ney Latorraca. "Primeiro dia de gravação... Feliz. Agora em casa descansando. Beijo a todos e obrigada pelo apoio. Amo vocês", escreveu Nicole no Twitter após a gravação.
}

\section{Uso sincrético de imagens}

De um lado, temos um texto que relata de forma descontraída e simplista como o diretor tentou colocar a mão dentro do vestido da apresentadora. Do outro lado, temos imagens que mostram um homem com a mão entre as pernas de uma mulher, indefesa e 
coagida por estar diante das câmeras (Figura 01). A sequência de imagens é incômoda e perturbadora, até chegar às últimas imagens da reportagem, onde a apresentadora foi fotografada sentada, a partir de um ângulo em que é possível enxergar sua calcinha (Figura 02). Por mais que a sequência de imagens sugira o mesmo que o texto, que Nicole Bahls teve o que mereceu, o conteúdo visual é chocante, suscitando questionamentos em relação ao acontecimento. A função das imagens era ancorar o texto, porém, tomaram sentido próprio devido à agressividade da cena.

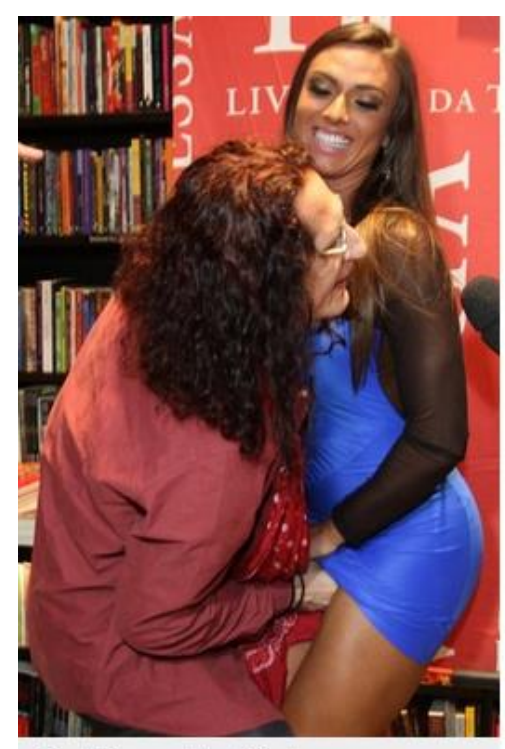

Gerald Thomas 'ataca' Nicole

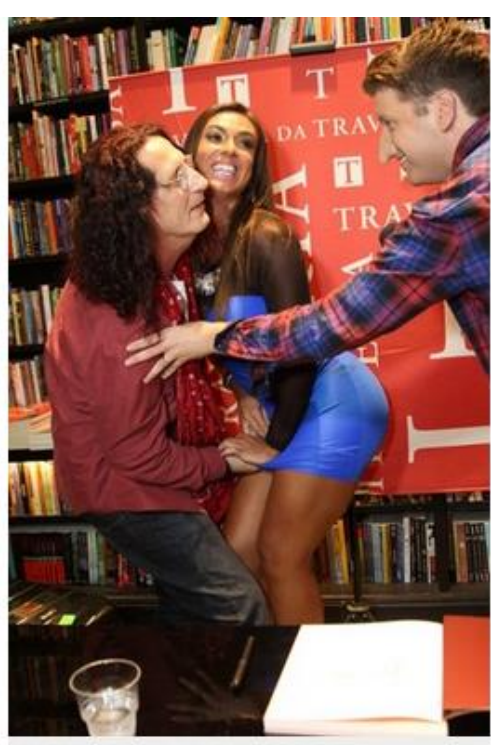

Nicole Bahls se defende de Thomas

Figura 01

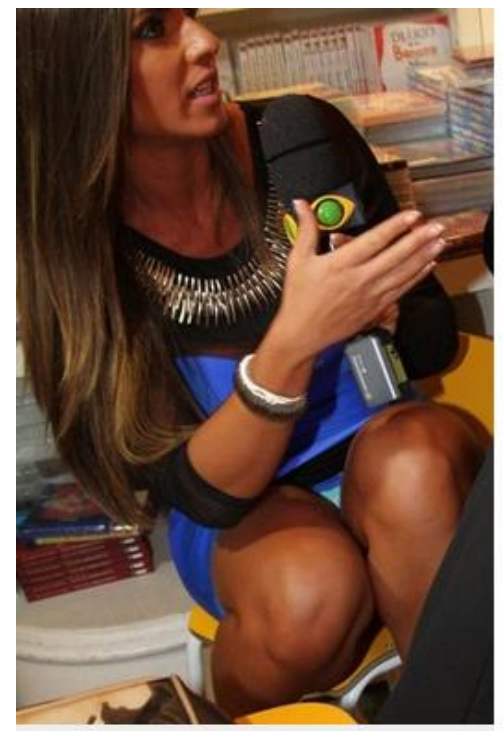

Nicole Bahls em lançamento de livro no Rio

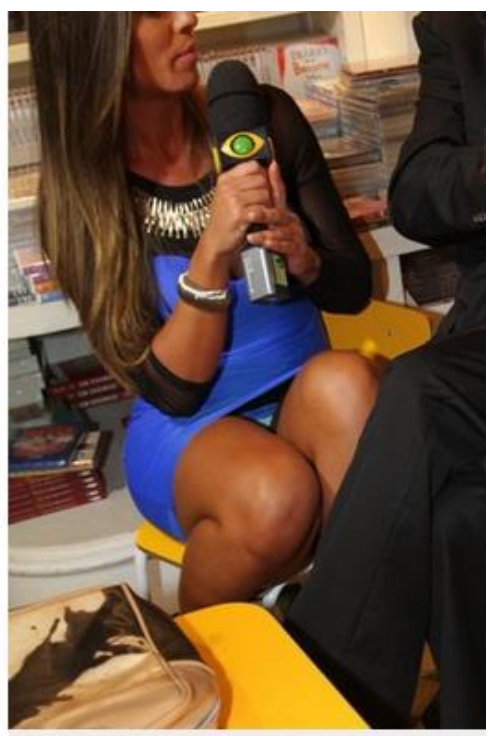

Nicole Bahls deixa calcinha à mostra

Figura 02 


\section{Folha de São Paulo}

Coluna Tony Goes

Na sua postagem sobre o ocorrido entre Nicole Bahls e Gerald Thomas, intitulada "Assédio de Gerald Thomas foi contra a caretice dos dias de hoje", Tony Goes traça paralelos entre o episódio e suas próprias opiniões e conhecimentos sobre o programa Pânico na TV, Nicole Bahls e sobre o diretor. Utilizando-se de linguagem coloquial e irônica, critica ainda a forma com que a sociedade e outros veículos se portaram diante do fato.

\section{Quanto ao modo discursivo}

Abordando o mesmo acontecimento, o autor traça seu argumento através da perspectiva de que a sociedade não entendeu o humor da situação e tudo não passou de um golpe de marketing, tanto do diretor quanto do programa Pânico, sendo assim, identifica-se em seu discurso o acontecimento comentado.

\section{Quanto ao conteúdo do texto}

Os períodos utilizados pelo autor durante o texto são em sua maioria simples, dando ritmo e atenuando o sarcasmo do mesmo. Através de orações subordinadas, Tony Goes amarra os parágrafos para desenvolver seu argumento. A estrutura do texto se dá da seguinte maneira:

$1^{\text {a }}$ parte: $\mathrm{O}$ autor começa o texto apresentando e definindo o programa Pânico a partir de seu próprio ponto de vista, baseado em suas vivências, dialogando com os leitores:

\footnotetext{
Você já esteve em algum evento invadido pelo pessoal do 'Pânico'? Eu já. O clima que se instaura entre anfitriões e convidados é, literalmente, de pânico. Os caras não vão lá para levantar a bola de ninguém. Querem mais é deixar as pessoas bem constrangidas, e depois humilhá-las em rede nacional. Muitas vezes o resultado que se vê na TV é engraçado. Muitas vezes não é. E algumas celebridades, já escoladas por uma década de perseguição pelos humoristas do programa, aprenderam a lidar bem com tal assédio (GOES, 2013).
}

$2^{\mathbf{a}}$ parte: A seguir, define o diretor e estabelece uma clara separação entre ele e o programa já apresentado, posicionando Gerald Thomas um nível acima do Pânico, defendendo assim que sua atitude foi condizente diante da abordagem feita pelos personagens, que tiveram seus codinomes citados para afirmar distancia intelectual entre eles e o diretor:

Duvido que Gerald Thomas passe seus domingos à noite assistindo à atração comandada por Emílio Surita. Duvido ainda mais que o público habitual do programa faça alguma ideia de quem seja Geraldo Thomas. De qualquer forma, o diretor teatral -um dos mais inovadores e importantes do Brasil-- reagiu à altura quando viu sua noite de autógrafos 'prestigiada' pelas presenças de Nicole Bahls, "Tucano Huck" e "Mecome Bahls" (GOES, 2013). 
$3^{\mathbf{a}}$ parte: Analisando o fato como uma simples performance teatral, o autor cita vários outros acontecimentos polêmicos da mesma noite, criticando o posicionamento de outros blogueiros sobre o mesmo fato:

\begin{abstract}
Sim, ele encoxou Nicole, e ainda tentou enfiar a mão por baixo da saia da moça. Mas também tentou abrir a braguilha de 'Tucano' e mostrou o próprio pênis para os fotógrafos. Desculpa, gente, mas isto não é tentativa de estupro. Nem faz parte da cultura do estupro, como teve blogueira mimimi repetindo por aí. Foi uma performance teatral, ousada e imprópria, feita propositalmente para mexer com a plateia (GOES, 2013).
\end{abstract}

$4^{\mathrm{a}}$ parte: Ainda defendendo seu argumento de que tudo não passou de pura encenação, Tony Goes critica a reação de Nicole Bahls através de esteriotipação e comparação:

Nicole não gostou. Disse que se sentiu agredida, e está em seu pleno direito de se sentir como quiser. Muitos espetáculos agridem mesmo: o teatro não é feito só de comédias inofensivas para a classe média rir antes de ir para a pizzaria. Mais do que suas formas voluptuosas, o que a recontratada panicat revelou mesmo foi uma falta espantosa de jogo de cintura. Logo ela, que deu uma canseira nos demais participantes da 'Fazenda de Verão'. Talvez fosse o nervosismo pela reestreia no programa. Só sei que, se Sabrina Sato estivesse em seu lugar, provavelmente teria dado um rolé em Gerald Thomas (GOES, 2013).

$5^{\mathbf{a}}$ parte: Após situar e definir cada um dos personagens dentro do cenário proposto, o autor coloca sarcasticamente como o ocorrido acabou gerando divulgação gratuita para todos os envolvidos:

Para variar, o episódio foi bom para todos os envolvidos: tanto o 'Pânico na Band' quanto Bahls e Thomas ganharam bastante mídia gratuita na semana passada. $\mathrm{O}$ blog do diretor bateu seu recorde de audiência e, glória suprema, seus detratores criaram uma página no Facebook para melhor atacá-lo. E o programa dedicou boa parte de suas três horas de duração neste domingo (14) à repercussão do caso na imprensa e nas redes sociais. Repercussão esta que foi amplamente negativa, misturando uma correção política meio fora de lugar com ignorância sobre os personagens em questão (GOES, 2013).

$\mathbf{6}^{\mathbf{a}}$ parte: Para finalizar, justifica seu ponto de vista e define seu posicionamento na discussão:

Que uma coisa fique bem clara: sou totalmente contra a cultura do estupro (que existe mesmo), e jamais direi que mulheres que se vestem de maneira provocante 'merecem' sofrer qualquer tipo de violência. Só acho que não foi isto o que aconteceu neste caso. É preciso contextualizar: saber quem são os gozadores do 'Pânico', e saber também quem é Gerald Thomas, ele também um gozador. Já fomos bem menos caretas e malhumorados do que hoje (GOES, 2013). 


\section{Uso sincrético de imagens}

A imagem principal da matéria é a mesma utilizada pelo site EGO, mostrando a cena entre Nicole e Gerald (Figura 01). Já as imagens veiculadas ao final da matéria são uma coletânea de vários momentos na carreira de Nicole Bahls (Figura 03). Porém, têm função de revezamento ao complementar sentido do texto, mostrando a apresentadora através do estereótipo colocado pelo autor, uma vez que as fotos retratam Nicole sempre com roupas curtas e coladas ao corpo, em posições provocativas.

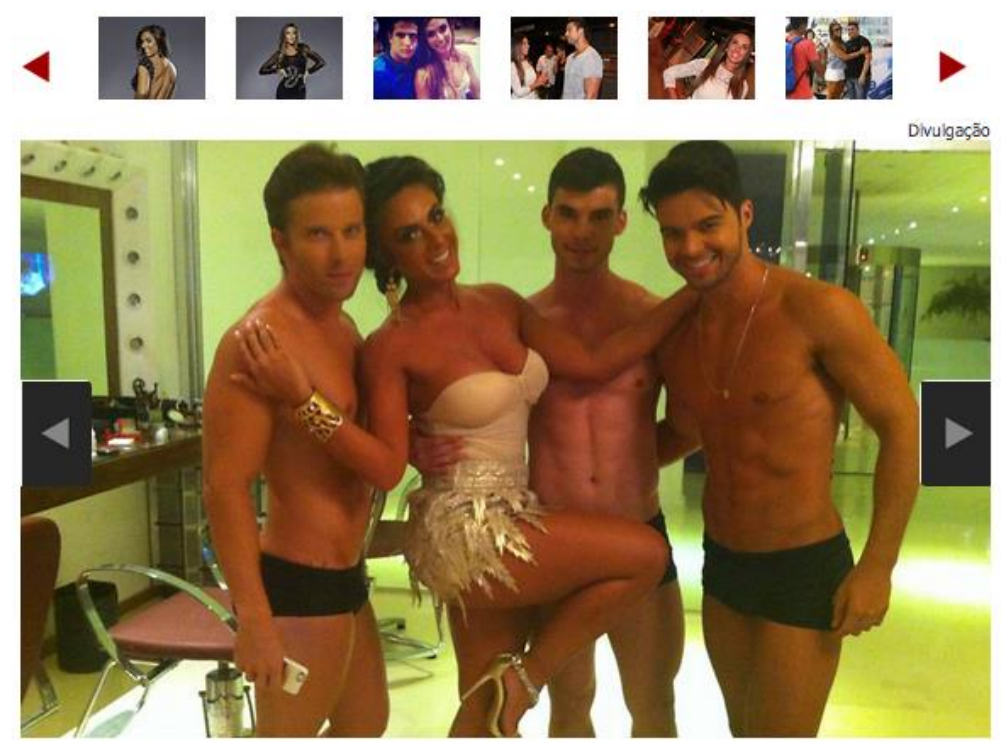

Figura 03

\section{Carta Capital}

\section{Quanto ao modo discursivo}

A advogada, jornalista e blogueira Nádia Lapa é autora do livro "Cem homens em um ano - As aventuras sexuais de uma mulher bem resolvida", relatou detalhes de seus encontros casuais, ficou conhecida em 2011 como Letícia F e contava suas aventuras no blog Cem Homens. É autora dos blogs Cem Homens, Cem homens sem noção e Cem canções. A ideia de conhecer e se relacionar com cem homens em um ano e publicar essas experiências em um blog se transformou em livro. No caso em questão a autora utiliza o acontecimento comentado em seu texto, tratando-o como um caso de estupro, ou seja, de agressão às mulheres.

\section{Quanto ao conteúdo do texto}

No texto “A cultura do estupro gritando - e ninguém ouve” escrito por Nádia Lapa, a organização é feita da seguinte forma: 
$1^{\text {a }}$ parte: A autora faz a apresentação do fato que será discutido no texto, que se dá da seguinte forma:

Era noite de lançamento de um livro dele e a Livraria da Travessa estava lotada. Repórteres, cinegrafistas, funcionários da loja, clientes. Pelas notícias, ninguém fez nada. Nas imagens dá para ver que o colega de trabalho de Nicole no Pânico continuou a entrevista como se nada tivesse acontecendo. Enquanto isso, Thomas também de enfiava a mão entre as pernas de Nicole e ela tentava se desvencilhar". E também aborda sobre "Sempre rolam os xingamentos à mulher, claro. São os usuais: que ela estava pedindo, que ela estava gostando, que o trabalho dela é esse mesmo, que a roupa era justa. Vocês estão cansados de saber quais as justificativas injustificáveis para o assédio e a agressão sexual.

$2^{\mathbf{a}}$ parte: Aponta duas questões sobre o caso, sendo a primeira "é ninguém ter feito nada. Acharem normal. Acharem aceitável. Se a agressão tivesse sido com uma atriz considerada recatada, as pessoas reagiriam da mesma forma?", a segunda "é terem dito "mas por que ela não fez algo?"'. Estas duas questões abordadas pela autora no texto, mostram tanto quem faz a ação como quem sofre a ação, pois o ocorrido foi tratado de forma a mostrar a ação do diretor de teatro como uma ação constrangedora e não como uma ação agressiva reforçando o tratamento da mulher como coisa e/ou objeto. Neste caso havia ainda a justificativa de que Nicole Bahls provocou o que aconteceu, naturalizando o ocorrido por ela ser quem é. E não se discutiu sobre o fato de que a tendência das pessoas que sofrem qualquer tipo de agressão é a omissão. A autora também aponta a dificuldade da uma vítima em "encarar polícia, legista, imprensa, opinião pública", e além disso, nesse caso em específico, o agravante de que a agressão aconteceu diante dos colegas de trabalho e das câmeras, e ninguém fez nada.

Nadia ainda questiona o leitor com a seguinte pergunta: "Se fosse você a vítima, você não pensaria que a errada é você por não estar gostando, já que todo mundo está achando muito normal?", promovendo uma discussão sobre agressão x constrangimento, agressor x vítima e como a sociedade respondeu ao acontecimento.

$3^{\text {a }}$ parte: Analisa a cultura do estupro, considerando que este "é um processo social, coletivo, mas também individual", pois para que isso aconteça é preciso que "encarar nossos corpos como nossos e de mais ninguém, além de repensarmos o sexo, transformando-o no que realmente é: prazeroso e consensual. Qualquer coisa fora disso é agressão”.

\section{Uso sincrético}

No texto de Nádia Lapa não há suporte de imagens. 


\section{Análises transversais}

No dia 11 de abril, no site “dialetica.org”, Marcos Donizetti publicou um texto intitulado "Gerald Thomas, Nicole Bahls, misoginia e culpa", buscando uma abordagem mais profunda e abrangente sobre o ocorrido, observando o fato e suas raízes sociais, que de acordo com a análise proposta nesse artigo foi o que fomentou os discursos expostos.

O fato de Gerald Thomas ser um diretor de teatro conhecido por suas polêmicas e Nicole Bahls por sua carreira como modelo e assistente de palco de programa de TV não altera a discussão sobre a cena protagonizada. Nas reportagens apresentadas, a discussão perpassa em justificar e culpabilizar as ações dos envolvidos nesta polêmica, pois traz à tona a discussão sobre a culpabilidade da vítima aos olhos do agressor e da própria sociedade na qual está inserida. A reflexão desses dois pontos auxilia a entender como a mesma notícia no foi publicada nos três diferentes portais analisados, onde cada um define a mesma situação de três formas distintas: "algo não esperado", "algo contra a caretice" e "cultura do estupro".

É importante ressaltar que os discursos apresentados abordam, de formas e recortes diferentes, as duas análises feitas por Donizetti em seu texto. Na primeira parte o autor disserta sobre "O homem que estupra e/ou justifica o ato pela culpa da vítima", explicando que a justificativa ocorre porque a mulher é uma ameaça ao homem que a violenta e a sua identidade, então, a violência contra ela surge do desejo que o ameaça e precisa ser calado. A culpa da vítima é justificada a partir da premissa que essa deveria cobrir seu corpo e comportar-se devidamente, de acordo com as normas de conduta social, para não provocar a violência contra ela.

\footnotetext{
Natural, infelizmente, que uma sociedade machista adote esse posicionamento de "proteção do macho" de forma tão massiva, é o discurso da misoginia. A moça é culpada por "provocar". Ao fazê-lo, fica claro a esse indivíduo que ele não tem controle ou poder sobre esses estímulos tão "perigosos". Nessa fantasia infantil, a moça malvada opta diabolicamente por não cumprir o contrato (DONIZETTI, 2013).
}

O fator social fica claro, pois esse discurso é aceito e acatado dentro de uma sociedade dominantemente machista, onde o homem como voz dominante deve ser protegido e resguardado para não ceder aos seus instintos, e nunca confrontado a lidar com eles, promovendo devido respeito e limites entre os gêneros. Percebe-se que à mulher são estabelecidos limites que devem ser obedecidos para que o homem não seja provocado a ceder ao seu instinto, mas do homem não se exige nada, uma vez que o foco de controle está sobre a mulher, e assim, a ordem social é mantida. 
A segunda parte da análise trata sobre como a própria mulher culpa a vítima nesses casos, e como o autor ressalta, “boa parte das mulheres são ‘vetores de transmissão’ do discurso machista" (DONIZETTI, 2013), revelando que a norma social imposta para o comportamento feminino na sociedade e as penalidades caso essas normas sejam desobedecidas já são estatutos sociais.

A imposição social do discurso machista e a culpabilidade da mulher em situações como o ocorrido entre Nicole Bahls e o Gerald Thomas fica explícita na matéria do site EGO, onde a justificativa do ato do diretor se encontrava no comprimento da saia e no comportamento da apresentadora, como se a roupa curta da apresentadora fosse um passe livre para que fosse apalpada por um sinal de que era isso que ela queria.

Os comentários dos leitores mostram como essa justificativa é acatada pela sociedade, e conforme a Figura 04, e tomada como verdade social. Outro ponto que chama a atenção é que o comentário em questão foi feito por uma mulher, e é apenas um exemplo de vários outros contidos na mesma publicação.

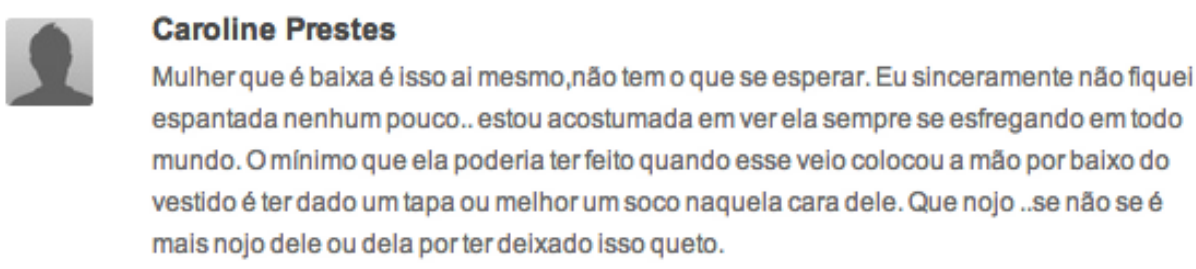

Figura 04

É nesse ponto que se debate a abrangência do discurso machista patriarcal tão estruturante e latente na cultura brasileira, refletido no discurso jornalístico. Aceitar o que aconteceu com Nicole vai além do ocorrido naquela noite, coloca em pauta a forma como a mulher é estereotipada e coagida diariamente na sociedade onde o homem apodera-se de seu papel dominante para naturalizar a desigualdade social entre os gêneros. Donizetti apresenta a extensão social atingida pela defesa desse discurso da seguinte forma:

O que essas mulheres não sabem é que a manutenção desse discurso e desse estado de coisas as torna vítimas, mesmo que não exista o abuso, o ato violento. São tão vítimas, submetidas a isso, quanto aquelas que culpam. O salto necessário, e difícil, é saber que a única culpa real é a de não lidar e não se responsabilizar pelo próprio desejo (DONIZETTI, 2013). 


\section{Considerações Finais}

O mesmo acontecimento pode gerar diferentes tipos de discursos. Percebe-se que, enquanto alguns veículos se limitam a simplesmente noticiar os fatos de sua própria perspectiva, sem pretensão de fomentar outras discussões, outros se apoderam delas para trazer à tona questões sociais profundas e relevantes.

$\mathrm{Na}$ análise foi possível identificar diferentes enunciações partindo de um único fato. Ao noticiar o fato como uma simples "saia justa", o site EGO, o veículo mais popular analisado, afirmou a posição de Nicole como mulher objeto que estava ali para ser usada pelo diretor, indo ao encontro da mentalidade da cultura machista, tão latente no cenário brasileiro. Em contra partida, Nádia Lapa seguiu a linha crítica da revista Carta Capital, utilizando-se do episódio noticiado pelo EGO para levantar a questão da imagem da mulher e do estupro dentro dessa mesma cultura brasileira. Tony Goes, por sua vez, olhou para as opiniões expressas e, colocando-se no patamar de especialista, caracterizou o acontecimento como um grande golpe de marketing, reafirmando a existência da cultura machista e ainda lançando ao leitor a culpa de olhar para o fato de forma crítica, dizendo nas entrelinhas que o ocorrido é aceitável dependendo de como e de onde se observa.

Nos três os casos, o leitor leu a leitura feita anteriormente por cada autor, que caracteriza a estratégia autorreferencial da enunciação jornalística, uma tentativa de fazer com que o sentido compreendido seja aquele que é enunciado, visando um leitor como receptor passivo e mantenedor do discurso proposto.

Porém, como apontado por Fausto Neto, observa-se uma dualidade nesse processo, onde de um lado tem-se a homogeneidade dos processos de produção de sentidos nas enunciações jornalísticas, e do outro observa-se justamente a heterogeneidade dos atores e dos processos de recepção, apontada no presente artigo, onde diante da quantidade de informação disponível, o leitor deixa de ser um sujeito passivo para ser um "novo sujeito interpretativo". (Artigo enviado em 02/12/2013, aprovado em 20/12/2013)

\section{Referências}

CHARAUDEAU, Patrick. Discurso das mídias. São Paulo: Contexto, 2012.

ORLANDI, Eni Pulcinelli. Análise do discurso: princípios e procedimentos. 9. ed., Campinas, SP: Pontes, 2010.

FAUSTO NETO, Antônio. Enunciação, auto-referencialidade e incompletude. Revista FAMECOS. Porto Alegre, n.34, p.78-85, dez. 2007. 
EGO. Gerald Thomas enfia a mão dentro do vestido de Nicole Bahls. EGO, Rio de Janeiro, 2013. Publicada em 10/4/2013 atualizada em 11/4/2013. .Disponível: http://ego.globo.com/noite/noticia/2013/04/escritor-enfia-mao-dentro-do-vestido-denicole-bahls.html < Acessado em abril de 2013> GOES, TONY. Assédio de Gerald Thomas foi contra a caretice dos dias de hoje. Folha de S. Paulo, 2013.Portal F5 UOL. Colunista Tony Goes. Publicado em 15/04/2013 08h45. Disponível: http://f5.folha.uol.com.br/colunistas/tonygoes/1262735-assedio-degerald-thomas-foi-contra-a-caretice-dos-dias-de-hoje.shtml $<$ Acessado em abril de 2013>

LAPA, Nádia. A cultura do estupro gritando - e ninguém ouve. Carta Capital, São Paulo, 2013. Coluna Sociedade. Publicado em 11/04/2013 - 17h17. Disponível:

http://www.cartacapital.com.br/sociedade/a-cultura-do-estupro-gritando-e-ninguemouve/ < Acessado em abril de 2013>

DONIZETTI, Marcos. Gerald Thomas, Nicole Bahls, misoginia e culpa. Portal Dialetica.org. Acessado em abril de 2013. Disponível:

http://dialetica.org/donizetti/gerald-thomas-nicole-bahls-misoginia-eculpa/?utm_source=dlvr.it\&utm_medium=twitter 